\title{
ANÁLISE DO DEBATE PARLAMENTAR SOBRE O "INFANTICÍDIO" INDÍGENA
}

\author{
Gabriel Pereira Penna Andrade \\ Autor correspondente. Universidade Federal de Viçosa - UFV. Av. Peter Henry Rolfs, s/n - Campus Universitário. Viçosa/MG, Brasil. \\ CEP 36570-900. http://lattes.cnpq.br/2760993065632943. https://orcid.org/0000-0003-1408-1633. gabriel.andrade@ufv.br

\section{Edson Ferreira de Carvalho} \\ Universidade Federal de Viçosa - UFV. Viçosa/MG, Brasil.
}

O presente artigo busca empreender o debate acerca da prática conhecida como infanticídio indígena, com foco na elaboração do Projeto de Lei 1.057/2007, que cria formas de combater sua ocorrência. Para tanto foi realizada uma pesquisa documental, procurando evidenciar a relação entre as premissas feitas, suas bases fáticas e modificações no Projeto. Por fim, os resultados foram analisados com o prisma teórico da Legisprudência (WINTGENS, 2006) e da Teoria Crítica dos Direitos Humanos (HERRERA FLORES, 2009; DOUZINAS, 2013). O estudo permitiu concluir que as discussões apagaram possibilidades que não passavam pela via legislativa, ignoraram a ausência de dados para subsidiar a proposta e seguiram uma postura intransigente que dificultou a participação efetiva dos afetados.

Palavras-chave: direitos humanos; povos indígenas; infanticídio; poder Legislativo; debate parlamentar.

\section{AN ANALYSIS OF THE PARLIAMENTARY DEBATE REGARDING THE INDIGENOUS “INFANTICIDE” ABSTRACT}

This article aims to understand the debate regarding the practice known as indigenous "infanticide", focusing on the making of the Bill no 1.057/2007, that creates ways to fight against its practice. To do so, we carried out a documentary research, seeking to put in evidence the connexions between the assumptions made, their factual basis and the changes performed at the bill. Lastly, we analyzed the results using the theories of Legisprudence (WINTGENS, 2006) and of the Critical Theory of Human Rights (HERRERA FLORES, 2009; DOUZINAS, 2013). The study concluded that the debate obliterated all the possibilities but the legislative way, ignored the lack of data capable of giving support to the bill and had an uncomplying stance that turned the effective participation of those affected by it harder.

Keywords: human rights; indigenous peoples; infanticide; Legislative power; parliamentary debate. 


\section{Humanos e \\ Democracia}

\section{INTRODUÇÃO}

No dia 10 de junho de 2006 o deputado Henrique Afonso ocupou a tribuna da Câmara dos Deputados do Brasil para discursar em plenário durante o período das comunicações parlamentares. Falou sobre o caso da menina Iganani e sua mãe Muwaji, indígenas da etnia Suruwahá, do Estado do Amazonas. Iganani, segundo o orador, havia nascido deficiente e seria sacrificada por sua tribo caso a mãe não tivesse se manifestado contra a prática, desafiando as crenças de sua comunidade e recorrendo a missionários evangélicos para que as levassem para tratamento médico no hospital Sarah Kubitschek, em Brasília. O deputado, então, afirmou ter sido surpreendido por descobrir que muitas outras etnias indígenas matavam seus recém-nascidos, fato que deveria ser debatido "à luz da Antropologia, da Teologia e de qualquer outra ciência". Por fim, acrescentou que esperava

que neste país, em que tantas coisas ruins têm acontecido, a campanha contra o infanticídio ganhe força, porque, afinal de contas, são crianças indefesas que, repito, pelo fato de terem nascido gêmeas, com deficiência física ou por causa do código cultural de suas etnias, são destinadas ao sacrifício. Que Deus possa nos encorajar para encamparmos essa luta (CÂMARA DOS DEPUTADOS, 2006)

Esta foi a primeira manifestação em plenário que colocava o chamado "infanticídio indígena" como problema generalizado que deveria ser combatido. O chamado "infanticídio" é, na verdade, tecnicamente classificado como homicídio de recém-nascidos, ${ }^{1}$ uma prática cultural atribuída a algumas etnias indígenas por diversas razões, como nascimento de gêmeos, de deficientes, de filhos tidos como havidos fora do casamento ou pela crença de que o neonato traria infortúnio à comunidade (ROSA, 2014).

A partir da fala do deputado Afonso, o infanticídio ganhou a agenda legislativa e passou a ser fonte de conflitos dentro das instâncias legiferantes. Em 2007 o mesmo deputado apresenta em plenário o Projeto de Lei 1.057/2007, apelidado justamente de Lei Muwaji, que teria como objeto "o combate a práticas tradicionais nocivas e à proteção dos direitos fundamentais de crianças indígenas, bem como pertencentes a outras sociedades ditas não tradicionais". O projeto foi aprovado pela Câmara dos Deputados em 2015 e ainda não foi analisado pelo Senado. ${ }^{2}$

O debate foi impulsionado em grande parte pela ONG Atini, um movimento contra o infanticídio fundado por missionários que trabalhavam com os Suruwahá. Em 2008 o grupo lançou o docudrama Hakani em parceria com o grupo missionário Jovens com uma Missão (Jocum), que contaria a história de uma garota de mesmo nome que havia sobrevivido à prática. O filme foi criticado pelas organizações indigenistas, que viram na obra a exploração da imagem de membros de etnias indígenas que não praticavam o infanticídio e que foram usados como atores, o que motivou inclusive uma Ação Civil Pública por parte do Ministério Público Federal (SANTOS-GRANERO, 2011; MINISTÉRIO PÚBLICO FEDERAL, 2015).

\footnotetext{
Embora atécnica, será mantida a denominação "infanticídio", visto se tratar de termo consolidado na literatura sobre o tema.

2 A tramitação do projeto refere-se até o dia 14/12/2018.
} 


\section{Humanos e \\ Democracia}

Rodrigues (2013) revisa as posições científicas sobre o infanticídio classificando-as, conforme sugerido por Gutmann (1993), em três paradigmas: universalismo abrangente, que acredita haver princípios aplicáveis a todos os seres humanos independentemente da cultura e do contexto histórico; relativismo cultural, que nega radicalmente essa premissa, e relativismo político, que defende o uso de meios institucionais para criar deliberações sobre dissensos internos que têm por objeto os significados culturais. $O$ autor consegue encontrar as três posições no debate acadêmico sobre infanticídio, com destaque para a ampla filiação dos membros do movimento Atini ao universalismo abrangente (RODRIGUES, 2013).

O presente artigo também fará uma revisão do debate, propondo-se a mapear o debate parlamentar. Tem por objetivo, desta maneira, evidenciar como se dão as relações entre as bases fáticas, as posições defendidas pelos atores envolvidos (legisladores, poder Executivo e sociedade civil) e suas consequências legislativas. Por razões práticas, o enfoque do artigo será o PL 1.057/2007 que, embora não tenha sido o único projeto de lei que teve por assunto o infanticídio indígena, foi aquele tido como simbólico para o debate e o único que atualmente se encontra em tramitação.

Visto que será mencionado o poder Legislativo dentro de seu poder legiferante, é importante recuperar as contribuições de Luc Wintgens (2006) no campo da teoria da legislação ou, como o autor a denomina, Legisprudência. Para o autor, a teoria estatal clássica do contrato social, que justifica qualquer restrição em conceitos "de liberdade" (of freedom, dados pelos indivíduos para si mesmos sem restrições legais) em nome de uma soberania que permitiria ao Estado criar conceitos superiores "sobre liberdade" (about freedom, dados externamente a partir da lei), é incorreta a partir do momento em que não considera a liberdade de indivíduos e grupos como princípio reitor da produção jurídico-normativa. Por conseguinte, o conflito é apresentado como necessariamente maléfico em vez de um fato social produtor de significados, consequência da própria complexidade plural da vida em sociedade. Assim, cria-se um modelo estatal descolado da realidade que coleta a vontade dos cidadãos no momento de sua formação e após age indiscriminadamente em nome da soberania, em que a ideia de democracia afasta o próprio conceito de povo, e cuja única fonte de legitimação da norma é uma hipotética procuração fornecida pela totalidade dos cidadãos em passado remoto (WINTGENS, 2007).

A atividade legislativa, segundo a Legisprudência, não é ação arbitrária do legislador, que deve compreender o problema e suas alternativas e escolher a solução mais adequada para manter a higidez do ordenamento jurídico e a liberdade dos indivíduos e da sociedade civil. O entrelaçamento entre os fatos que levaram à criação da norma, os argumentos para sua elaboração e sua estrutura final formam, por conseguinte, um emaranhado inseparável cuja coerência é essencial para a legitimação da norma. Sob esse prisma, é possível analisar a produção de leis a partir da tríade problemas (que englobam os substratos fáticos que levam ao desejo de legiferar), representações sobre o problema (que criam as soluções legais para o tema) e forma final da legislação.

Dessa maneira, propõe-se um modelo de compensação (trade off) em que toda restrição à liberdade pessoal deve ser justificada em termos racionais. Assim, o legislador precisa (i) demonstrar que a lei regula uma situação que não pode ser regulada de outra maneira (princípio da alternatividade); (ii) que as sanções eventualmente aplicáveis são estritamente 


\section{Democracia}

Humanos e

necessárias (princípio da densidade normativa); (iii) que a norma é adequada ao seu tempo e contexto (princípio da temporalidade) e (iv) que ela guarda coerência com o sistema jurídico (princípio da coerência) (WINTGENS, 2006).

Por se tratar de tema que perpassou várias comissões e tomou diversas formas, optou-se por fazer um apanhado geral das representações legislativas sobre o infanticídio em vez de focar somente na tramitação do PL 1.057. O trabalho, entretanto, procura sempre mostrar como os debates e o Projeto de Lei se influenciaram mutuamente durante sua análise pelos deputados.

A metodologia utilizada parte da análise documental por categorias de dois corpora ${ }^{3}$ inter-relacionados, quais sejam, os dados de tramitação do PL 1.057/2007 e os documentos e discursos apresentados no Congresso Nacional sobre infanticídio. No caso do primeiro, integram o corpus o projeto original, todos os relatórios, as emendas apresentadas, as notas taquigráficas do debate de votação no Plenário da Câmara dos Deputados e as notas taquigráficas da audiência pública realizada na Comissão de Direitos Humanos e Legislação Participativa do Senado Federal. Para o segundo, foi realizada em 26/7/2018 busca nas bases de dados "Projetos de Lei e outras proposições" e "Discursos" da Câmara e nas bases "Pronunciamentos" e "Projetos e Matérias" do Senado Federal pelos termos "infanticídio indígena", "Atini, "Hanaki" e "Muwaji". O inteiro teor dos documentos encontrados, quando indisponível nas bases citadas, foi solicitado via Lei de Acesso à Informação. ${ }^{4}$

Os documentos pertencentes aos dois corpora foram analisados procurando se responder às seguintes perguntas: (i) Qual a posição manifestada pelo autor?; (ii) Quais os argumentos desenvolvidos?; (iii) Qual a base fática dos argumentos e suas fontes?; (iv) Como os argumentos e fatos contribuem para o debate sobre infanticídio (em especial a partir da comparação dos dois conjuntos de texto)?

A estrutura do artigo compreende, de início, discussão sobre a posição do sujeito indígena dentro do ordenamento jurídico brasileiro. Em adição, faremos uma breve incursão no tema dos direitos humanos e suas críticas de esquerda, uma vez que o terreno dos direitos humanos é uma disputa importante dentro do debate sobre infanticídio. Depois desta exposição teórica, passa-se aos resultados e suas discussões, que serão divididos nos requerimentos de informação, nas audiências públicas e na tramitação da Lei Muwaji propriamente dita.

\section{A LEGISLAÇÃO INDIGENISTA: Entre A Integração e o Reconhecimento}

A história do Direito Indigenista no Brasil tem caminhado entre dois polos: de um lado, a visão do indígena como menor, atrasado, o "selvagem" que, ao ser "domesticado" por meio da aculturação perde sua identidade indígena, visão que se denomina "integracionista", e o indígena como parte de um povo que, apesar de distinto culturalmente, integra a sociedade como igual e cujo conhecimento e costumes são importantes para a cultura nacional, posição conhecida como "de reconhecimento" (BARRETO, 2014, p. 33-44).

\footnotetext{
O corpus, cujo plural é corpora, é, segundo Bardin (2011, p. 126), "o conjunto dos documentos tidos em conta para serem submetidos aos procedimentos analíticos".

4 Requerimentos com o protocolo 180719-000155 e 180723-000134.
} 


\section{Humanos e \\ Democracia}

Fazendo a reconstituição da legislação indigenista brasileira, Souza Filho (1992) relaciona o início da política integracionista a um alvará de 1775 , que declarava que o casamento entre europeu e indígena não traria nem ao casal nem à sua descendência nenhuma infâmia, lançando as bases para a mentalidade legal de que a integração do indígena ao modo de vida europeu seria benéfico à sua existência. Além dessa norma, tem-se uma Carta de Lei de 1831 que afirmava que os indígenas feitos cativos por ocasião de guerras deveriam ser libertados e entregues ao juízo de órfãos. Tal comando, entretanto, passou a ser interpretado de maneira geral, de forma que todos os indígenas passaram a ser tutelados pelo juízo de menores (SOUZA FILHO, 1992).

Em período mais recente tem-se como exemplo de legislação integracionista a Lei 6001/73, o Estatuto do Índio (EI), ainda em vigor (BARRETO, 2014, p. 33-44; BRASIL, 1973). O diploma legal em questão mostra sua lógica ao definir indígena como indivíduo pertencente a grupo étnico cujas características o distinguem "da" (e não "na") sociedade e Comunidade Indígena ou Grupo Tribal como sendo necessariamente comunidades não integradas à "comunhão nacional" (artigo 3ำ, El). Além disso, o artigo 4일 divide os indígenas em isolados, em vias de integração e integrados, deixando claro que a integração seria o ponto de chegada da lei.

A virada rumo ao reconhecimento ocorre com a Constituição Federal de 1988. A partir dela, o Direito Indígena que, além de integracionista, privilegiava somente a posse da terra, em uma postura que Barreto (2014, p. 97-100) denomina de privatista, passa a ser pluridimensional, agregando outros direitos como a língua e a cultura (cf. artigos. 231 e 232 da CF/88). Ela cria, como bem expõe Souza Filho (2013, p. 4.667), um direito de que cada comunidade decida sobre seu livre desenvolvimento dentro de suas próprias visões de mundo.

A inércia do legislador em criar leis infraconstitucionais consagradas pelo constituinte originário, entretanto, levou a um preenchimento da legislação indigenista constitucionalmente adequada por convenções internacionais, em um processo chamado de "convencionalização do Direito dos Povos Indígenas" (HEEMANN, 2017). Assim, documentos internacionais, nem todos vinculantes, como a Convenção 169 da Organização Internacional do Trabalho, a Convenção Americana de Direitos Humanos, a Declaração da ONU Sobre os Direitos dos Povos Indígenas e a Declaração Americana sobre Direitos dos Povos Indígenas passam a fazer parte dos subsídios legais para decisões judiciais e políticas públicas sobre povos indígenas. Destes, destaca-se a Convenção 169/OIT, promulgada pelo Decreto 5.051 de 2004, que possui ampla gama de direitos e é de cumprimento obrigatório (HEEMANN, 2017).

O ordenamento jurídico indigenista brasileiro permanece, contemporaneamente, composto de diplomas dissonantes. De um lado, tem-se a "tutela-incapacidade", colocada pelo Estatuto do Índio, que determina ser função do Estado tutelar somente o indígena considerado "não integrado", incapaz de ser autônomo perante a sociedade como um todo; de outro, tem-se a Constituição e os documentos internacionais que estabelecem a "tutela-proteção", entendendo o indígena como ser humano vulnerável, ainda que autônomo e digno e, dessa maneira, carente de proteção da mesma maneira que mulheres, trabalhadores e crianças, por exemplo (BARRETO, 2003).

Embora a Constituição e a Convenção 169 possuam status superior ao Estatuto do Índio, a mentalidade dos aplicadores do Direito permanece pendendo para o integracionismo e para a tutela-incapacidade, o que leva Souza Filho (1992) a caracterizar o Direito dos Povos 


\section{Democracia}

Humanos e

Indígenas como um "Direito Envergonhado", em que a teoria é plural e democrática, porém a prática permanece eurocêntrica e sectária. De fato, ao observar os estudos empíricos de Becker, Souza e Oliveira (2013) sobre o direito à perícia antropológica no Processo Penal, e Oliveira (2016) e Rebelo e Raio (2017) sobre a proteção da criança indígena, é possível concluir que a mentalidade institucional tende a considerar a identidade indígena como inferior e passível de ser apagada por completo em razão do convívio com o meio externo à comunidade de origem.

\section{OS DIREITOS HUMANOS E A HEGEMONIA}

A influência que o discurso sobre direitos humanos tem no campo político atual é crescente. Para Moyn (2010), os direitos humanos são vistos como a última utopia do ser humano, promessas ainda inalcançáveis que, não obstante, continuam a influenciar de forma considerável o pensamento jurídico de todos os países, cujas leis são endossadas ou rejeitadas segundo esquema dado a priori que seria aplicável a todos as nações, identidades coletivas ou momentos da História humana. Nas palavras de Boaventura de Sousa Santos (2013), os direitos humanos são uma "frágil hegemonia", um discurso ao mesmo tempo potencialmente dominador e emancipatório, inafastável do Direito contemporâneo e que deve, por isso, ser construído de forma contra-hegemônica pelos excluídos dentro do mundo capitalista e globalizado.

As críticas aos direitos humanos como conceito vêm em duas frentes: à direita, os direitos humanos são criticados principalmente por serem abstratos e não terem relação com um ser humano real; à esquerda, a crítica geral se inverte, e os direitos humanos ganham um aspecto dominador, fruto de uma classe que é burguesa, ocidental e masculina e que apaga quaisquer outras formas de subjetividade (TOSI; SCORPION, 2017).

É nesse último sentido que Douzinas (2009) argumenta que os direitos humanos, na condição de ideologia dominante do "fim da história", são repletos de paradoxos, causando sua própria crise. Assim, a mentalidade de resistência política contra o Estado e seu poder se transforma em uma estrutura jurídica complexa de normas e organizações internacionais e nacionais que trazem em seu bojo a negação do caráter político dos direitos humanos; a sua promessa de liberdade transforma-se em controle biopolítico quando a lei invade todos os aspectos da vida social; a razão universal e a proclamação do homem se dissolvem diante dos movimentos identitários e à descolonização; e o chamado "Século dos Direitos Humanos" é também o século do Genocídio de Ruanda (DOUZINAS, 2009, 2013). A reformulação dos direitos humanos passa, dessa maneira, por uma redefinição política e conceitual que não faça uma opção cínica pelo universalismo sem tomar o caminho perigoso do particularismo absoluto, que coloque a alteridade como centro da ética e da normatividade do Direito e permita sua construção não a partir de um fim na História, mas de um caminho contínuo guiado pelas demandas alheias por dignidade (DOUZINAS, 2009).

De maneira semelhante, Herrera Flores (2006) pondera que o colonialismo apaga a diferença ao homogeneizar e inferiorizar as culturas da periferia do capital e ignora sua própria estrutura histórica por meio da criação de um humanismo abstrato que se transforma em demonstração de poder ocidental. Esse humanismo é base para o cometimento de ações que negam a ele mesmo sob o pretexto civilizatório, gerando graves violações de direitos cometi- 


\section{Democracia}

Humanos e

das por potências em países subdesenvolvidos ou em desenvolvimento e por grupos internos dominantes sobre minorias. Os direitos humanos devem ser compreendidos, dessa maneira, como processo histórico e contínuo em que a luta de grupos pelos bens materiais e imateriais necessários a sua subsistência geram mudanças na ordem jurídica e social. Aqui, a chave não é um "universalismo de partida", como quer a ideologia dominante dos direitos humanos, nem um "universalismo de retas paralelas", que essencializa as identidades ao colocar grupos como culturas estanques e isoladas com poder absoluto de autodeterminação, mas um "universalismo de chegada", em que a interação intercultural gera novas formas de subjetividade e conquistam demandas para grupos vulneráveis (HERRERA FLORES, 2002, 2009).

Nesse ponto, Boaventura de Sousa Santos (1997) cria uma metodologia que permite o debate intercultural, ao qual ele denomina "Hermenêutica Diatópica". A metodologia parte da concepção de que cada cultura possui seus topoi, lugares argumentativos que dentro de sua lógica cultural própria são tidos como inquestionáveis. Ocorre que as culturas, e por consequência os topoi que as informam, são incompletas, podendo ser modificadas dentro da dinâmica social. Caberia aos grupos, dessa maneira, influenciar reciprocamente seus topoi em um procedimento dialético, contínuo, horizontal e recíproco, permitindo maior completude de ambas as formas de ver o mundo.

Dentro do debate sobre qual a extensão do poder estatal soberano diante das suas minorias nacionais, essas ponderações são importantes por demonstrar que a pluralidade de formas de ver o mundo também gera pluralidade de soluções para os conflitos entre grupos, e que uma metodologia horizontal e contra-hegemônica traz, em seu arcabouço, não só compromissos éticos com a alteridade como propõem formas inovadoras de pacificação de conflitos.

\section{RESULTADOS E DISCUSSÃO}

\subsection{Os Requerimentos de Informação}

Requerimento de Informação (RIC) é uma modalidade de requerimento prevista no artigo 50, §2º, da Constituição Federal de 1988 e regulada pelo artigo 116 do Regimento Interno da Câmara dos Deputados e 216 e 217 do Regimento Interno do Senado. Os RICs são, como explicitam Mendes e Branco (2017), consequência da função fiscalizadora do poder Legislativo e do sistema de freios e contrapesos típicos da forma republicana dentro do Estado de Direito, estando previsto o direito de demandar informações ao Executivo mesmo em Constituições autoritárias como a advinda da Emenda Constitucional no 1 de 1969 (AZEVEDO, 2013). Sua importância é tamanha que o decorrer do prazo de 30 dias sem resposta importa crime de responsabilidade para o ministro responsável por fornecê-la (artigo 50, §2으, CF/88). A presente pesquisa encontrou quatro requerimentos de informação relativos ao infanticídio indígena: os RICs 672 e 673/2007, do deputado Marcelo Serafim (PSB/AM), o RIC 1543/2011 do deputado Takayama (PSC/PR) e o RIC 4159/2014, do deputado Arolde de Oliveira.

Os RICs 672 e 673/2007 foram dirigidos à Fundação Nacional do Índio (Funai) e à Fundação Nacional de Saúde (Funasa), respectivamente, demandando se (i) era de conhecimento das Fundações que existiam aldeias que cometiam o infanticídio; (ii) qual o número de crianças mortas devido ao infanticídio nos últimos cinco anos; (iii) quais tribos praticavam o 


\section{Democracia}

Humanos e

infanticídio e, no caso do RIC 672, (iv) quais providências a Funai tomava para coibir a prática. A justificativa de ambos os requerimentos é idêntica, e utiliza uma reportagem da Revista Veja como subsídio para a existência da prática, asseverando ser o infanticídio ato contrário ao Ordenamento Nacional e Internacional (SERAFIM, 2007a, b).

Em resposta, a Funai informou que não tinha dados sobre a prática, cuja coleta demandaria tempo e recursos humanos e materiais, além de pessoal técnico com capacitação para atuação em territórios indígenas. Em adição, a Fundação lembrou que o Ordenamento Nacional e Internacional defende a necessidade de respeitar costumes e tradições indígenas, e que a Funai deve seguir essas normativas.

Já a Funasa emitiu Nota Técnica de número 033/2008/GAB/Desai, em que expõe que a Fundação utiliza como registro da mortalidade infantil a Classificação Internacional de Doenças (CID-10), que não possui a categoria infanticídio. Ademais, o infanticídio, na condição crime contra a vida, não é de competência da Funasa, ente administrativo responsável pela política de saúde indígena. Por fim, argumenta que a Fundação criou, em 2008, Comissões Distritais para Investigação de Óbitos Infantis e Fetais para subsidiar políticas públicas. Em despacho que encaminha a Nota Técnica para o Departamento de Saúde Indígena, órgão da Funasa, o autor da nota afirma ainda que a resposta deveria ser avaliada pela administração por envolver "interesses privados de igrejas evangélicas atuantes junto a comunidades indígenas".

Embora a Funasa afirme não ter dados de infanticídio em comunidades indígenas, o Ofício 892/Aspar/Presi/Funasa do presidente da Funasa para o chefe de Assessoria Parlamentar do Ministério da Saúde possui um anexo com dados de infanticídios por Distrito de 2003 a 2007, citando como fonte o Departamento de Saúde Indígena da Funasa. Os dados mostram a ocorrência de infanticídio somente em dois distritos, ressaltando que, em um deles, ocorreram somente dois casos, podendo concluir que o infanticídio é prática restrita geográfica e culturalmente.

O Requerimento de Informação 1.543 de 2011 do deputado Takayama (PSC/PR) foi dirigido à Funai e tem como escopo questionar (i) qual o número de crianças indígenas vítimas de infanticídio devido ao nascimento com deformações congênitas, outra condição de saúde ou de crianças gêmeas; (ii) qual o órgão ou o setor responsável pelo levantamento desses dados e (iii) com que periodicidade esse levantamento é realizado e qual o método de coleta de dados utilizado. Como justificativa, o autor alega que o infanticídio, apesar de documentado por diversos estudos, não possui dados quanto à sua prevalência, sendo necessárias informações que subsidiem o debate público sobre a prática. Por fim, citou dados do Ministério da Saúde para mostrar que a mortalidade infantil indígena era bem mais alta que da população em geral e que grande parte das causas era desconhecida.

Em resposta, a Funai afirmou que não havia, no requerimento, menção de quais estudos afirmavam a existência da prática, que não havia justificativa plausível para levantar a prevalência do infanticídio devido à inexatidão de sua ocorrência e, portanto, que não havia órgão responsável pelo levantamento e que a Funai realizou frequentemente trabalhos junto aos Conselhos Tutelares e às Varas da Criança e do Adolescente com o intuito de proteger a criança indígena. 


\section{Democracia}

Humanos e

O RIC 4.159/2014, de autoria do deputado Arolde de Oliveira (PSD/RJ), dirigido ao Ministério da Defesa, teve como objetivo requisitar dados sobre as causas da alta taxa de mortalidade infantil em áreas atendidas por hospitais militares, em especial em São Gabriel da Cachoeira/ AM. O parlamentar pediu informações sobre (i) o número de crianças indígenas nascidas vivas nos hospitais militares em todo o Brasil nos últimos cinco anos, detalhando as regiões e, se possível, os hospitais; (ii) o número de crianças indígenas que morreram nos últimos cinco anos nos hospitais militares em todo o Brasil; (iii) as causas das mortes; (iv) a existência de registros de crianças que chegaram aos hospitais vítimas de práticas culturais que as levaram à morte e quais foram essas práticas; ( $v$ ) o número de crianças nascidas com deficiência física ou mental ou de gravidez gemelar, o seu acompanhamento pela equipe de saúde e a aceitação por seus povos e (vi) a existência ou não de registros de óbitos de crianças indígenas elaborados por equipes de saúde fora dos hospitais, por equipes que trabalham em áreas indígenas, indicando, em caso positivo, o número registrado, as causas das mortes e as regiões e/ou aldeias.

O Ministério da Defesa informou que não havia registros de mortes por motivos culturais e nem de rejeição de crianças por parte de tribos, ressaltando que o trabalho in loco era feito pela Funasa nas aldeias.

\subsection{Audiências Públicas e Consulta aos Povos Afetados}

A Audiência Pública é instituto previsto de maneira ampla na Constituição Federal de 1988 , em seu artigo 58, §2으. II, e regulamentada em seus pormenores nos artigos 255 a 258 do Regimento Interno da Câmara dos Deputados e 93 a 95 do Regimento Interno de Senado Federal. Trata-se, como bem registra Moreira Neto (1992), de procedimento de democracia participativa que ganha relevo na atual ordem constitucional.

O debate sobre a participação popular amplia-se no pós-Segunda Guerra, quando a queda do fascismo e seu questionamento à democracia como instituição dá lugar à discussão não mais sobre a validade do modelo, mas sobre como, em uma sociedade que se complexifica a cada dia e cujo crescente grau de tecnologização ameaça a própria noção de soberania do povo, pode-se criar um sistema de governo guiado não pela legalidade pura e simples, mas também pela noção de legitimidade, entendida aqui como a correspondência da delegação, execução e finalidade do poder com as vontades sociais dominantes. A Audiência Pública, nesse contexto, é instituto que garante parcela da capacidade jurídica do cidadão de, caso queira, alcançar as instâncias de decisão para tentar modificá-las (MOREIRA NETO, 1992).

No caso das populações tuteladas pela Convenção 169 da OIT há um fator obrigatório adicional de participação, que se trata do Direito à Consulta e ao Consentimento Prévio, Livre e Informado (DCCPLI) inscrito no artigo 60 do referido dispositivo. ${ }^{5}$ Trata-se de mecanismo dis-

\footnotetext{
Artigo 6o: 1. Na aplicação das disposições da presente Convenção, os governos deverão: a) consultar os povos interessados, por meio de procedimentos adequados e, em particular, de suas instituições representativas, sempre que sejam previstas medidas legislativas ou administrativas suscetíveis de afetá-los diretamente; b) criar meios pelos quais esses povos possam participar livremente, ou pelo menos na mesma medida assegurada aos demais cidadãos, em todos os níveis decisórios de instituições eletivas ou órgãos administrativos responsáveis por políticas e programas que lhes afetem; c) estabelecer meios adequados para o pleno desenvolvimento das instituições e iniciativas próprias desses povos e, quando necessário, disponibilizar os recursos necessários para esse fim. 2. As consultas realizadas em conformidade com o previsto na presente Convenção deverão ser conduzidas de boa-fé e de uma maneira adequada às circunstâncias, no sentido de que um acordo ou consentimento em torno das medidas propostas possa ser alcançado (OIT, 2011, p. 18-19).
} 


\section{Democracia}

Humanos e

tinto das audiências públicas e outras formas previstas regimentalmente pelo Legislativo Federal, diferindo-se na forma da consulta e em sua obrigatoriedade (ROJAS GARZÓN; YAMADA; OLIVEIRA, 2016). Segundo Peruzzo (2017), a consulta prévia é direito público subjetivo das comunidades indígenas, cristalizada pela legislação internacional com o objetivo de diminuir a distorção de anos de dominação física, política e cultural dessas comunidades. O Direito à Consulta cria mecanismos dialéticos amplos, em que todas as etapas são negociadas e direcionadas para o consenso, revelando-se essencial a comunicação não violenta. ${ }^{6}$

A plasticidade do instituto da consulta prévia, embora imprescindível para garantir o respeito às especificidades culturais de cada população, impõe grande desafio para o Estado, que precisa determinar quem serão os afetados e quais metodologias devem ser as escolhidas. Por vezes essas metodologias são colocadas a priori pelas próprias populações e desenhadas segundo suas tradições e vivências. Dessa forma, enquanto para os Wajãpi o processo envolve funcionários com poder de decisão que devem ficar alguns dias na aldeia (APINA; APIWATA; AWATAC, 2014), o protocolo Krenak estipula que as reuniões não devem durar mais de um dia (KRENAK, 2017). Como se depreende do artigo 60 da Convenção 169, a consulta prévia não é somente fator de legitimidade da decisão mas, antes, etapa obrigatória para que esta seja legal, tratando-se de um procedimento legislativo da mesma natureza de uma votação, por exemplo.

Foram encontrados seis requerimentos de audiências públicas, das quais cinco foram realizadas nas Comissões de Direitos Humanos e Minorias (CDHM), Seguridade Social e Família (CSSF) e Defesa dos Direitos das Pessoas com Deficiência da Câmara dos Deputados e na Comissão de Direitos Humanos e Legislação Participativa do Senado Federal. ${ }^{7}$

Em relação ao direito à consulta, não foi encontrada qualquer menção a sua realização em nenhum dos documentos que compõem o corpus analisado. Somado a isso, o relatório sobre a situação dos povos indígenas enviado ao Conselho de Direitos Humanos da Organização das Nações Unidas por organizações da sociedade civil menciona que o processo de tramitação do PL 1.057/2007 não contou com consulta (APIB; RCA; DHESCA BRASIL, 2016), o que permite concluir que o projeto teve sério vício de forma.

Um primeiro aspecto importante a se considerar para as audiências públicas é a sua composição. Conforme explicitado anteriormente e posto pelos regimentos das duas Casas, a audiência pública é local de pluralidade, em que todas as visões sobre o assunto devem ter espaço para apresentar suas posições (RICD, art. 256, §1ㅇe e RISF, art. 94, §1으). Apesar disso, os requerimentos foram em geral pobres de diversidade, com a participação de pessoas não indígenas favoráveis ao projeto, membros da ONG Atini, indígenas ou não, e indígenas que

\footnotetext{
É importante destacar que, embora a consulta não permita um poder de veto, como já explicitado por jurisprudência tanto da Corte Constitucional colombiana como do Supremo Tribunal Federal brasileiro (BIM, 2014), a boa-fé da consulta exige que o governo explicite as razões pelas quais descumpre a vontade expressa no processo e busque as medidas menos danosas para a comunidade que será afetada (ROJAS GARZÓN; YAMADA; OLIVEIRA, 2016).

Foram encontradas (i) duas audiências na Comissão de Direitos Humanos e Minorias, fruto dos Requerimentos 20/2007 CDHM e 92/2008 CDHM e realizadas nos dias 5/9/2007 e 27/11/2008, respectivamente; (ii) uma audiência na Comissão de Seguridade Social e Família, fruto dos Requerimentos 332/2009 CSSF e 25/2011 CSSF e realizada no dia 14/06/2011; (iii) uma audiência realizada na Comissão de Direitos Humanos e Legislação Participativa do Senado, a única a tratar diretamente da Lei Muwaji, fruto do Requerimento RDH 8/2016 e realizada em14/11/2016; e (iv) uma audiência na Comissão de Defesa dos Direitos das Pessoas com Deficiência, fruto do Requerimento 103/2017 CPD e realizada em 24/5/2017.
} 


\section{Democracia}

Humanos e

vivenciaram o infanticídio, além da Funai e da Funasa. Não houve nenhuma previsão nos requerimentos de participação de entidades que trabalhem com a questão indígena, como o Conselho Indigenista Missionário, entidades representativas, como o Conselho Nacional de Mulheres Indígenas ou entidades de classe, como a Associação Brasileira de Antropologia e a Ordem dos Advogados do Brasil. Alguns atores não governamentais, como Maíra de Paula Barreto (doutora em Direito pela Universidade de Salamanca), Ronaldo Lidório, (antropólogo $)^{8}$ e Márcia Suzuki e Eli Ticuna (Movimento Atini), foram repetidamente convidados. Todos esses agentes eram favoráveis ao PL 1.057/2007. Por duas vezes membros do Parlamento foram interpelados para que houvesse audiências com outras entidades, sem que isso realmente tenha acontecido. ${ }^{9}$

Embora tenha havido restrição de participantes nos requerimentos, em duas das audiências, a convocada pelo Requerimento 20/2007 no âmbito da Comissão de Direitos Humanos e Minorias da Câmara dos Deputados e a convocada pelo Requerimento 8 de 2016 no âmbito da Comissão de Direitos Humanos e Legislação Participativa do Senado Federal, houve a participação maior de diversos segmentos sociais. A primeira contou com a participação de não indígenas contrários ao PL 1.057/2007 (Rita Segato, antropóloga) e com representante do Fórum em Defesa dos Direitos Indígenas (Valéria Payê) e das mulheres indígenas no Conselho Nacional dos Direitos das Mulheres (Jacimar de Almeida Gouveia), enquanto que a segunda, ainda que não tenha contado com lideranças nacionais dos povos indígenas, contou com expositora contrária à proposta (Marianna Assunção, antropóloga). No polo oposto, não houve sequer convocação de entidades governamentais no Requerimento 92/2008 da Comissão de Direitos Humanos e Minorias, e a audiência se realizou somente com expositores favoráveis ao PL 1.057/2007. Já a audiência pública solicitada pelos requerimentos 332/2009 e 25/2011 da Comissão de Seguridade Social e Família da Câmara, embora tenha convidado um representante governamental, este não compareceu, tendo a mesa a mesma composição homogênea da anterior.

As justificativas dos requerimentos de audiência também são importantes para entender sob quais condições se desenvolve o debate sobre infanticídio. Em geral, baseiam-se em fontes indiretas e suposições para argumentar que o infanticídio é prática corriqueira dentro das tribos indígenas brasileiras. Assim, o REQ 20/2007 CDHM explicita que "existem centenas de casos de crianças indígenas sacrificadas" (AFONSO, 2007a, p. 2), enquanto que os REQs 92/2008 CDHM, 332/2009 e 25/2011 CSSF citam o relatório da CPI da Subnutrição de Crianças Indígenas para sustentar que a desnutrição tem, em pelo menos parte considerável dos casos, causas culturais, chegando a afirmar que "[d]urante os trabalhos daquela CPI os parlamentares foram surpreendidos com uma causa mortis de crianças indígenas que para muitos até então era apenas uma lenda. Trata-se do infanticídio praticado por algumas etnias brasileiras por motivações culturais" (DR. TALMIR, 2009, p. 1).

\footnotetext{
Lidório por duas vezes enviou como representante Edward Luz, também antropólogo.

9 As ocasiões em que houve esses pedidos foram durante a audiência convocada pelos Requerimentos 332/2009 e 25/2011 CSSF, feitos pela líder indígena Rosane Kaingang, e durante a audiência pública convocada pelo Requerimento 8/2016 da Comissão de Direitos Humanos e Legislação Participativa do Senado, feito pela antropóloga Marianna Assunção. A última consulta feita pela pesquisa sobre audiências públicas ocorreu em 1이일.
} 


\section{Humanos e \\ Democracia}

O relatório da $\mathrm{CPI}$, todavia, aponta como causas fundantes para a alta desnutrição problemas institucionais na Funai e na Funasa, conflitos por terras e desestruturação social (CÂMARA DOS DEPUTADOS, 2008, p. 186-196). Sobre o infanticídio, em especial, ele é descrito como tendo poucas informações (CÂMARA DOS DEPUTADOS, 2008, 190-191). Embora o próprio relatório da CPI constate que a prevalência da prática é desconhecida, o Requerimento 25/2011 CSSF afirma, sem citar fonte, que a audiência pública que requisita deve ser realizada com urgência, uma vez que "[há] evidência que inúmeras crianças indígenas são mortas mensalmente apenas por serem portadoras de deficiência ou de problemas de saúde" (LUCENA, 2011, p. 4).

As posições dentro das audiências foram relativamente homogêneas. Os defensores do projeto de lei não indígenas e os membros da ONG Atini argumentavam que o infanticídio não só era uma prática corriqueira como também que as demandas pelas mudanças normativas partiam dos próprios povos indígenas. Foram citadas cifras de "pelo menos 200 [infanticídios por ano]" (Márcia Suzuki, audiência REQ 20/2007 CDHM), "uma boa centena de crianças" (Edward Luz, audiência REQs 332/2009 e 25/2011 CSSF) e 30 etnias que o praticam e provavelmente mais de mil crianças mortas por ano ${ }^{10}$ (Damares Alves, Movimento Atini, audiência REQ 103/2017 CPD). Entre os indígenas prevaleceu o relato sobre situações pessoais com o infanticídio e a demanda por políticas públicas de forma ampla, sem necessariamente adentrar no assunto do PL 1.057/2007. Os argumentos legais foram praticamente inexistentes, com exceção das falas feitas por Maíra Barreto (audiências REQ 20/2007 CDHM e RDH 8/2016).

Já no que respeita aos expositores contrários ao projeto, os argumentos centraram-se (i) no fato de o infanticídio ainda ser mal compreendido, não havendo razões para considerá-lo prática típica de povos indígenas; (ii) que o protagonismo indígena e o diálogo em direitos humanos são mais eficientes do que a imposição legal do ponto de vista moral, principalmente tendo em vista a história de dominação colonial; (iii) que o PL 1.057/2007 era, em especial, uma forma de dominação que descendia da dominação colonial; (iv) que há outros problemas que têm sido ignorados pelo Congresso Nacional, como o sucateamento das agências indigenistas; (v) que a lei estigmatiza os povos indígenas; (vi) que é impossível de ser aplicada dada a estrutura das agências governamentais e que, inclusive, dificulta as ações indigenistas ao criminalizar qualquer pessoa que deixe de denunciar uma "situação de risco" e (vii) que é inócua, visto que suas previsões já teriam base legal.

As intervenções de parlamentares foram em geral, com raras exceções, destinadas a ressaltar que as culturas são dinâmicas e que o direito à vida é direito garantido pela Constituição independentemente de origem social. Por vezes houve a reafirmação de dados apócrifos sobre infanticídio, como a cifra de 200 infanticídios/ano (Henrique Afonso, audiência REQ 20/2007 CDHM) e 20 etnias que a praticam (Rosinha da Adefal, audiência REQ 103/2017 CPD).

\footnotetext{
${ }^{10}$ Quanto à estimativa de mais de mil crianças, é importante ressaltar a título de comparação que, segundo os dados fornecidos pela Funasa no contexto do RIC 673, a mortalidade infantil por todas as causas de 2003 a 2007 não ultrapassou a casa das mil crianças.
} 


\section{Democracia}

Humanos e

\subsection{Análise Crítica do Projeto de Lei 1.057 de 2007}

O Projeto de Lei 1.057/2007 foi proposto pelo deputado Henrique Afonso, à época filiado ao Partido dos Trabalhadores do Estado do Acre. O projeto começa afirmando que o Estado respeita os costumes e as práticas de povos não tradicionais, desde que estes estejam em conformidade com os direitos humanos e fundamentais (artigo 19). Em seguida, passa a um rol exemplificativo das práticas consideradas nocivas incluindo, além de homicídio, abuso

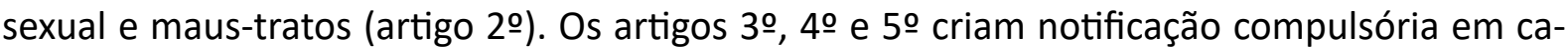
sos em que haja "suspeita ou confirmação de gravidez considerada de risco" ou "de crianças correndo risco de morte" tipificando, inclusive, o crime de omissão de socorro aos que não o fizerem. $\mathrm{O}$ artigo 60 estabelece o dever das autoridades judiciárias de retirar as crianças ou genitores do convívio do grupo, devendo encaminhar as primeiras para adoção caso o poder público não consiga convencer a comunidade a abdicar da prática tradicional. Por fim, o artigo7ํㅜ cria, de maneira ampla, o dever de realizar o diálogo em direitos humanos com vistas a abolir as práticas tradicionais chamadas "nocivas".

Na justificativa, o parlamentar cita uma série de recomendações internacionais que afirmam que os Estados-parte na ONU e na Convenção 169/OIT devem se esforçar para erradicar práticas tradicionais que sejam nocivas às crianças e aos adolescentes. Afirma o autor que

[s]abe-se que, por razões culturais, existe a prática de homicídio de recém-nascidos, o abuso sexual de crianças (tanto por parte de seus genitores quanto por parte de estranhos), a desnutrição intencional, entre outras violações a direitos humanos fundamentais. Destaca-se que tais práticas não se circunscrevem a sociedades indígenas, mas também a outras sociedades ditas não tradicionais (AFONSO, 2007b, p. 6).

Afirma ainda que, de acordo com a Funasa,

entre a etnia Yanomami, o número de homicídios elevou o coeficiente de mortalidade infantil de 39,56 para 121, no ano de 2003. Ao todo, foram 68 crianças vítimas de homicídio naquele ano. No ano seguinte, 2004, foram 98 as crianças vítimas de homicídio (erroneamente divulgado como infanticídio) (AFONSO, 2007b, p. 7).

Os dados apontados pelo autor destoam dos fornecidos posteriormente pela própria Funasa à Câmara dos Deputados, que apontou 74 e 58 mortes totais de crianças no Distrito Sanitário Especial Indígena (DSEI) Yanomami de 0 a 5 anos nos anos de 2003 e 2004 (NOTA TÉCNICA no 033/2008/Astec/Gab/Desai) e 22 e 16 mortes por infanticídio entre membros da etnia Yanomami em 2003 e 2004 (Oficio no 892/ Aspar/Presi/Funasa). Cita também um caso de gravidez resultante de estupro de uma índia Apurinã, referenciando notícia do portal Terra que em momento nenhum cita que a motivação decorreu de práticas tradicionais. ${ }^{11}$

Consta do Parecer no 01 CDHM, da deputada Janete Pietá, que o projeto peca ao (i) caracterizar pelo rótulo de "nocivas" as práticas tradicionais, o que estigmatizaria os povos indígenas; (ii) apresentar disposições penais, o que pode acabar inviabilizando o trabalho nas comunidades indígenas e (iii) não ter como foco o protagonismo dos povos indígenas na luta contra o infanticídio. Para justificar o ponto (iii), a relatora traz como subsídio a fala de Valéria

\footnotetext{
${ }^{11}$ A notícia está disponível em: <http://noticias.terra.com.br/brasil/interna/0,,OI949683-El306,00.html>. Acesso em 24 de outubro de 2017.
} 


\section{Democracia}

Humanos e

Payê feita por ocasião da audiência pública convocada pelo REQ 20/2007 CDHM, além de moção aprovada na II Conferência Nacional de Política para as Mulheres. Como solução, a relatora apresenta como única disposição a campanha pedagógica, citando um rol exemplificativo das práticas que deveriam merecer atenção. O Parecer 03/2009 CDHM apenas melhora a técnica legislativa, sem trazer avanço substancial. O Parecer 05/2011 CDHM não acrescenta nada na justificativa, mas cria em dois artigos o Conselho Nacional dos Direitos Indígenas (CNDI) e o Fundo Social Nacional dos Direitos Indígenas, sem explicitar suas funções. O Parecer 06/2011 CDHM entende que esses órgãos não podem ser criados por lei de iniciativa de parlamentares, mantendo a sugestão de sua criação no âmbito da justificativa. ${ }^{12}$

$\mathrm{Na}$ CCJC, o deputado Alessandro Molon cita uma série de normas nacionais e internacionais para comprovar que, do ponto de vista do ordenamento jurídico brasileiro, as práticas tradicionais que oferecem riscos às crianças e aos adolescentes devem ser coibidas, acrescentando que o texto da deputada Pietá criava uma legislação não autoritária e que se centrava no diálogo, recomendando, assim, sua aprovação.

O Plenário levou o projeto para direção bastante distinta das Comissões. Foram recebidas duas emendas integralmente aprovadas pelo relator em Plenário, deputado Marcos Rogério (PDT-RO), na forma de substitutivo. Enquanto a Emenda no 2 trazia poucas modificações ao projeto, permitindo apenas que entidades privadas pudessem auxiliar o poder Público na erradicação de práticas tradicionais nocivas, a Emenda no 1 , do deputado João Campos, representava uma volta ao projeto original, inclusive nas cláusulas de criminalização e retirada de crianças e genitores de suas comunidades. Além disso, aumentava o rol de incidência da norma para alcançar também mulheres e idosos e apresentava, em sua enumeração do que seria prática coibida, "estupro individual ou coletivo", "escravidão", "tortura" e "abandono de vulneráveis".

Do relatório, que acolheu as emendas, consta de forma ampla e genérica que o substitutivo aprovado na Comissão de Direitos Humanos e Minorias encontrava-se "desatualizado" diante das novas informações sobre a prática, sem discriminar quais seriam essas novas informações nem quais seriam as suas fontes. Importa acrescentar que, após a reafirmação do substitutivo da Comissão de Direitos Humanos e Minorias por meio do relatório da Comissão de Constituição e Justiça, ocorrida em 2/7/2013, a presente pesquisa não encontrou nenhum registro de audiência pública, tendo havido somente o Requerimento de Informação 4.159/2014 que, como já explanado, não acrescentou informações ao assunto. Dessa forma, se o relator teve contato com outras informações, essas lhe foram dadas de forma privada e sem oportunidade de contraditório, violando a própria estrutura dialética do processo legislativo democrático.

Em plenário, novamente, as opiniões incutidas foram relativamente homogêneas. Entre aqueles contrários à proposta havia quem defendesse o substitutivo da Comissão de Direitos Humanos e Minorias, alegando ser menos invasiva à cultura indígena e mais eficiente, e outros que defenderam a rejeição do texto, uma vez que a legislação já lidava com a questão,

\footnotetext{
12 Os pareceres no 2 e 4 são idênticos aos pareceres 1 e 3, respectivamente, não merecendo análise em separado
} 


\section{Democracia}

Humanos e

ainda que de forma inespecífica. Já aqueles favoráveis ao projeto afirmavam que, se existia conflito entre o direito à vida e a cultura, esta deveria sucumbir àquela.

No que diz respeito ao suporte fático, encontra-se nas notas taquigráficas (CÂMARA DOS DEPUTADOS, 2015b, p. 170) uma fala do deputado Sóstenes Cavalcante (PSD-RJ) que afirmava ser o infanticídio o responsável pelo aumento da taxa de homicídios da cidade de Caracaraí (Roraima) no ano de 2014, com o total de 37 infanticídios. A afirmação não tem suporte nos dados fornecidos pela plataforma DATASus, que apontam ter havido na cidade a morte de 15 crianças de zero a quatro anos por causas externas no período. ${ }^{13}$

O substitutivo do relator foi aprovado quase inteiramente, tendo sido suprimido apenas o §3으, que remetia ao artigo 21 do Código Penal, ${ }^{14}$ sobre as condutas de indígenas que cometessem ou se omitissem perante as práticas enumeradas como nocivas.

Em suma, o processo de tramitação do PL 1.057/2007 na Câmara dos Deputados parte de cinco pressupostos, a saber: (i) o infanticídio indígena é prática comum no Brasil, com centenas de crianças mortas todos os anos; (ii) o processo de criação deve ser dialético e ouvir todos os envolvidos; (iii) é necessário criar uma lei para regular a situação; (iv) trata-se de conflito entre a cultura e a vida, em que a primeira deve sucumbir diante da última; e (v) a lei deveria conter medidas coercitivas e de educação em direitos humanos.

Esses pressupostos retóricos são, entretanto, bastante criticáveis diante do prisma teórico adotado. No caso do argumento da alta prevalência do infanticídio, a ausência de dados oficiais sobre a prática deu lugar, na fala de deputados, a explanações e ilações sem fonte sobre práticas que inclusive exacerbam o objeto "infanticídio". ${ }^{15} \mathrm{Em}$ contraposição, outras questões importantes que poderiam ter sido abordadas em um substitutivo, como a alta mortalidade infantil indígena devido à desnutrição, foram ignoradas pelo Parlamento. ${ }^{16}$ Seria possível, por exemplo, que o projeto passasse a ser uma lei de prevenção à mortalidade infantil indígena, situação em que há dados e que abarcaria o infanticídio, o que de fato não foi a saída escolhida.

\footnotetext{
${ }^{13}$ Consulta realizada em 19 de outubro de 2018. Campos consultados: Óbitos por residência; Município: Caracaraí; Faixa etária: Menor 1 ano, 1 a 4 anos; Período: 2014. Disponível em: http://tabnet.datasus.gov.br/cgi/tabcgi.exe?sim/cnv/ext10rr. def

${ }^{14}$ Art. 21 - O desconhecimento da lei é inescusável. O erro sobre a ilicitude do fato, se inevitável, isenta de pena; se evitável, poderá diminuí-la de um sexto a um terço.

Parágrafo único - Considera-se evitável o erro se o agente atua ou se omite sem a consciência da ilicitude do fato, quando Ihe era possível, nas circunstâncias, ter ou atingir essa consciência (BRASIL, 1940).

${ }^{15}$ A título de exemplo, cita-se o discurso do deputado Roberto de Lucena feito no Plenário da Câmara no dia 19/4/2011, por ocasião do Dia do Índio. O deputado afirmou ter tomado conhecimento de que estaria entre as práticas indígenas o que ele chamou de "puxium", que consistiria no estupro coletivo de uma menina que acabasse de chegar na puberdade, afirmando estar reunindo informações sobre a prática para combatê-la. A presente pesquisa, em consulta realizada às bases de dados Scielo, Redalyc, Plataforma Capes e Google Acadêmico no dia 24/10/2017, não encontrou qualquer artigo científico que mencione o "puxium". Consulta realizada pelo buscador Google na mesma data não mostrou qualquer resultado em páginas não científicas da Rede Mundial de Computadores para a palavra além da própria transcrição do discurso. 0 termo não foi mais utilizado em Plenário e não há qualquer documento, nem do deputado Lucena nem de qualquer outro, que o utilize, segundo pesquisa realizada nos buscadores da Câmara dos Deputados.

${ }^{16}$ De fato, após 2008, ano de lançamento do relatório final da CPI da Desnutrição Infantil Indígena, houve somente um requerimento na Câmara dos Deputados para discutir a questão, e nenhum projeto de lei ou indicação. Pesquisa realizada em 28/10/2018 na base "Projetos de Lei e outras Proposições". Variáveis: ementa e indexação: presença da palavra "indígena" junto as palavras "desnutrição" ou "subnutrição" ou "mortalidade".
} 


\section{Democracia}

Humanos e

Seguindo, a afirmação de que o processo foi participativo também merece questionamento. Embora o relator em Plenário tenha afirmado que "[o] presente Projeto de Lei já foi amplamente discutido nesta Casa com a participação dos indígenas, da sociedade, [sic] e dos órgãos que desenvolvem as políticas indigenistas" (ROGÉRIO, 2015, p. 1), a análise dos dados mostra que a participação nas audiências públicas foi relativamente limitada, sem contar com participação ampla de alguns setores. Além disso, os argumentos apresentados em audiência pública, citados e valorizados pelos relatórios da Comissão de Direitos Humanos e Minorias, não constam do referido relatório que, em nome de uma suposta "melhor compreensão do processo", resgatou o projeto original. Também é importante mencionar que a Consulta aos Povos Indígenas Afetados, que se trata de condição mínima para garantir, além da legitimidade, a legalidade do processo legislativo, não foi realizada.

A falta de diálogo e dados idôneos e a aprovação de uma lei bastante coercitivista sobre o infanticídio podem ser, em adição, formas de escamotear as violências sofridas por minorias indígenas e reafirmar posições de poder. Os estudos de Page (2015) sobre a prática do fisi no Malawi trazem interessantes paralelos para a compreensão desse aspecto do debate sobre infanticídio. O fisi é uma prática tradicional em que um homem adulto é chamado para ter relações sexuais com uma jovem que menstruou recentemente. Dentro da sociedade malawi, a prática do fisi é tida como grande responsável pela ampla prevalência de HIV/Aids no país. A autora, porém, destaca que essa retórica sobre a prática, além de ter pouco embasamento científico, é usada para garantir à classe média malawi a manutenção de seus privilégios, visto que a maior parte deles depende do trabalho das ONGs no local para a sua subsistência. 0 resultado é a transferência da preocupação sobre o bem-estar feminino para uma suposta questão de saúde pública. No caso do infanticídio, a retórica de que a prática é comum também ajuda a apagar as violências diárias de várias dimensões sofridas pelos povos indígenas, tais como sucateamento dos órgãos indigenistas, genocídio e expulsão de suas terras. Quanto ao seu aspecto na manutenção de posições de poder, a presente pesquisa não tem subsídios para afirmar sua ocorrência, que pode ser usada como hipótese para futuros trabalhos.

A afirmação sobre a necessidade de lei é inconsistente por sugerir que somente por meio da atividade estatal legislativa é possível reduzir o infanticídio. Observa-se a negação de qualquer forma interna de organização com vistas a abolir a prática, organizações estas que inclusive já foram relatadas em audiência pública, conforme fala de Valéria Payê citada em todos os relatórios da Comissão de Direitos Humanos e Minorias:

Há 30 anos, acontecia isso [o infanticídio] com o meu povo. Não mais acontece, por força das nossas mulheres. Resolvemos, internamente. Não houve necessidade de imposições externas para isso ser feito. Não foi preciso uma lei do Congresso Nacional do Brasil para o povo Tiriyó, Katxuyana, Aparai e Wayana, até porque dizemos que a cultura não é parada. Em certos momentos, para os povos indígenas, na visão externa, ela tem de ser parada, tem de ser mantida daquele jeito, senão não é mais índio. Por outro lado, quando se quer atropelar o processo, construímos isso assim do jeito que está. Isso realmente me preocupa um pouco na condição de mulher (COMISSÃO DE DIREITOS HUMANOS E MINORIAS, 2007, p. 10).

Para além das formas não estatais de resolução da questão, também se pode questionar o uso da lei para combater o infanticídio. A lei, como expõe Thion (2007), não é mero 


\section{Democracia}

Humanos e

comando de dever-ser, mas guarda em si relações recíprocas com a mentalidade social dominante, uma vez que o imaginário ocidental lhe dá a pretensão de representação neutra dos fatos. A modificação geral e abstrata do Estatuto do Índio para adicionar um artigo que afirma que o poder público deve combater práticas como "homicídio de recém-nascidos" e "estupro individual e coletivo" dentro das coletividades indígenas pode criar a impressão de que essas práticas, consideradas isoladas e pontuais mesmo por aqueles que defendem o Projeto, são generalizadas, estigmando grupos já bastante vulneráveis dentro da sociedade.

O ponto sobre o necessário conflito entre a cultura e a vida parte do pressuposto de que há dois caminhos possíveis, ou seja, ou se é a favor do Projeto e contra o infanticídio ou se é contra o Projeto, o que significa ser a favor de sua prática. Essa linha de raciocínio ignora o amplo espectro de ações que pode ser usado pelo poder público para coibir a prática, além de partir para um maniqueísmo criticado pela literatura sobre multiculturalismo. Para usar a classificação de Herrera Flores anteriormente apresentada, o universalismo dessa premissa é de partida e coloca como única solução alternativa o "universalismo de retas paralelas", apagando de forma autoritária e hegemônica o "universalismo de chegada" que já foi, inclusive, largamente utilizado em países da América Latina para reformular suas ordens jurídicas a partir de conceitos de povos autóctones, como destaca Franco (2017). É importante salientar que as crianças indígenas são, para utilizar o termo citado por Green (1994), "minorias internas", possuindo todos os direitos de um indígena, inclusive a proteção cultural, fazendo jus a toda a tutela do Estado que sua natureza infantil lhe garante. Por conseguinte, tomar o caminho do ultimato "sua cultura ou seus direitos" é, como afirma Shachar (2004), não só moralmente problemático como também simplista diante da complexidade do mundo social e da subjetividade dessas pessoas.

Por fim, ao analisar o ponto sobre a necessidade de medidas coercitivas e educativas, é necessário ressaltar que o pressuposto foi praticamente abandonado pela Comissão de Direitos Humanos, que retirou medidas coercitivas e deixou somente a Educação em Direitos Humanos. A retomada das medidas coercitivas no Plenário, dessa maneira, representa uma violação clara ao princípio da densidade normativa citado anteriormente, uma vez que não há nenhuma justificativa específica para sua recriação. Novamente, a retórica uniforme dos apoiadores do PL, que coloca aqueles contrários ao Projeto como favoráveis ao infanticídio, gerou um debate raso quanto às possibilidades legais, não permitindo a criação de soluções inovadoras para a questão.

\section{CONCLUSÃO}

A presente pesquisa procurou compreender o problema do infanticídio sob a lógica metodológica documental, tendo por guia teórico três eixos contemporâneos importantes no Direito aplicável aos povos indígenas: a Teoria da Legislação e o fim do uso autoritário da soberania pelo legislador; as críticas de esquerda aos direitos humanos e o reconhecimento dessa classe como, ao mesmo tempo, potencialmente hegemônica e emancipadora; e o progressivo abandono da noção incapacitante do indígena na legislação indigenista brasileira, em especial com a convencionalização dos direitos indígenas.

A análise sob a ótica da Legisprudência apontou dois problemas principais no PL 1.057, quais sejam, a ausência de deliberação sobre formas alternativas à lei, violando o princípio da 


\section{Democracia}

Humanos e

alternatividade e a falta de justificação específica para o uso coercitivo de formulações legais, infringindo frontalmente o princípio da densidade normativa. A falta de dados precisos também é relevante para criticar legisprudencialmente o projeto, uma vez que o planejamento e a compreensão do problema são etapas essenciais para justificar de forma legítima a restrição nas liberdades do indivíduo e da sociedade civil por meio da lei.

As críticas à hegemonia dos direitos humanos nos permitem questionar o Projeto e sua tramitação na medida em que se coloca a solução como unívoca, sustentando que ou se acaba com a cultura supostamente infanticida ou se cria permissões estatais ao homicídio de recém-nascidos. É importante destacar que essa retórica apaga qualquer força modificadora que o intercâmbio cultural pode trazer a ambas as sociedades, extinguindo as identidades dissidentes e colocando a cultura majoritária, advinda do liberalismo que coloca um homem abstrato que, na verdade, se revela histórico e etnocêntrico, como superior a outras formas de sociabilidade.

Por fim, a narrativa legal trazida pela Constituição e pelos tratados internacionais que coloca o indígena como detentor de direitos coletivos e individuais que permitem manter sua cultura e cosmogonia é apagada pelo Projeto ao se ignorar completamente o direito à consulta prévia para os povos afetados, eivando de ilegalidade o processo legislativo, e ao criar rótulos estigmatizantes sobre povos bastante diversos entre si, uma vez que a expressão "povos indígenas" refere-se a um grande número de etnias. Para usar a classificação já exposta anteriormente, o Projeto 1.057 cria uma tutela-incapacidade sob a retórica de tutela-proteção, garantindo a perpetuação do poder hegemônico da maioria branca sobre essas minorias nacionais. Ao mesmo tempo, problemas estruturais como a falta de apoio do Executivo aos povos indígenas ou a grave mortalidade infantil por todas as causas entre as crianças indígenas são deixados de lado diante de um Projeto de impacto desconhecido, posto que desconhecida é a dinâmica do conflito a se regular.

Caberá ao Senado, na condição de Casa revisora do projeto, corrigir essas distorções que passaram despercebidas ou foram simplesmente ignoradas pelos deputados que aprovaram o projeto. Ao pautar a discussão sobre infanticídio por uma lógica contra-hegemônica e constitucionalmente adequada, os nobres senadores terão a oportunidade de reverter uma legislação opressora e trazer, ainda que parcialmente, a reparação histórica à qual os povos autóctones têm direito.

\section{REFERÊNCIAS}

\subsection{Documentos Citados}

AFONSO, H. Requerimento 20 de 2007 da Comissão de Direitos Humanos e Minorias. Brasília, 2007a. Disponível em: http://www.camara.gov.br/proposicoesWeb/fichadetramitacao?idProposicao=343576. Acesso em: 24 out. 2017.

AFONSO, H. Projeto de Lei 1.057/2007. Brasília, 2007b. Disponível em: http://www.camara.gov.br/proposicoesWeb/fichadetramitacao?idProposicao=351362. Acesso em: 24 out. 2017.

APIB; RCA; DHESCA BRASIL. A situação dos direitos humanos dos povos indígenas no Brasil: submissão conjunta para o terceiro ciclo de monitoramento do Brasil no Mecanismo de Revisão Periódica Universal do Conselho de Direitos Humanos da ONU. 2016. Disponível em: http://rca.org.br/wp-content/uploads/2016/11/RCA-2016-Relatorio-e-tabela-recomendacoes_-RPU-Coalizao-para-os-direitos-dos-povos-indigenas.pdf. Acesso em: 21 out. 2018. 


\section{Democracia}

Humanos e

APINA; APIWATA; AWATAC. Protocolo de Consulta e Consentimento Wajãpi. Macapá, 2014. Disponível em: http:// www.mpf.mp.br/atuacao-tematica/ccr6/documentos-e-publicacoes/protocolo-de-consulta-dos-povos-indigenas/docs/2014_protocolo_consulta_consentimento_wajapi. pdf. Acesso em: 20 out. 2018.

CÂMARA DOS DEPUTADOS. Discurso de Henrique Afonso na sessão 091.4.52.0 às $17 \mathrm{~h} 51$ do dia 1\%/6/2006. Brasília, 2006.

CÂMARA DOS DEPUTADOS. Relatório da Comissão Parlamentar de Inquérito destinada a investigar as causas, as consequências e os responsáveis pela morte de crianças indígenas por subnutrição de 2005 a 2007. Relator: Deputado Vicentinho Alves. Brasília, 2008. Disponível em: http://www2.camara.leg.br/atividade-legislativa/comissoes/comissoes-temporarias/parlamentar-de-inquerito/53a-legislatura-encerradas/cpindio/relatorio-final-aprovado-1/Relatorio.pdf. Acesso em: 24 out. 2017.

CÂMARA DOS DEPUTADOS. Notas taquigráficas da sessão deliberativa extraordinária 238.1.55.0, realizada em 25 de outubro de 2015. Brasília, 2015a.

CÂMARA DOS DEPUTADOS. Diário da Câmara dos Deputados. Brasília, a. LXX, n. 143, 27 ago 2015. 2015b. Disponível em: http://imagem.camara.gov.br/Imagem/d/pdf/DCD0020150827001430000.PDF. Acesso em: 23 ago. 2021.

COMISSÃO DE DIREITOS HUMANOS E MINORIAS. Notas taquigráficas da audiência pública no 1449/07. Brasília, 2007. Disponível em: http://www.camara.leg.br/internet/sitaqweb/TextoHTML.asp?etapa=11\&nuSessao=1449/07. Acesso em: 24 out. 2017.

DR. TALMIR. Requerimento 332 de 2009 da Comissão de Seguridade Social e Família. Brasília, 2009. Disponível em: https://www.camara.leg.br/proposicoesWeb/prop_mostrarintegra;jsessionid=node0qd45xrp9529b11je8xb smxe4k5792179. node0?codteor=712095\&filename=Tramitacao-REQ+332/2009+CSSF. Acesso em: 23 ago. 2021. KRENAK. Protocolo de consulta prévia ao povo Krenak. Resplendor, 2017. Disponível em: http://www.mpf.mp.br/ atuacao-tematica/ccr6/documentos-e-publicacoes/protocolo-de-consulta-dos-povos-indigenas/docs/ProtocoloConsultaKRENAK_.pdf. Acesso em: 20 out. 2018.

LUCENA, R. Requerimento 25 de 2011 da Comissão de Seguridade Social e Família. Brasília, 2011. Disponível em: http://www.camara.gov.br/proposicoesWeb/fichadetramitacao;jsessionid=8ACCBD89D4D6298B0665D16EC85651CE. proposicoesWeb1 ?idProposicao=496969\&ord=0. Acesso em: 24 out. 2017.

MINISTÉRIO PÚBLICO FEDERAL. Ação civil pública no 0009406-74.2015.4.01.4100. Porto Velho, 2015.

ROGÉRIO, M. Parecer 01 do Plenário ao PL 1.057/2007. Brasília, 2015.

SERAFIM, M. Requerimento de Informação 672 de 2007. Brasília, 2007a. Disponível em: https://www.camara. gov.br/proposicoesWeb/fichadetramitacao?idProposicao=363173. Acesso em: 14 dez. 2018.

SERAFIM, M. Requerimento de Informação 673 de 2007. Brasília, 2007b. Disponível em: https://www.camara. gov.br/proposicoesWeb/fichadetramitacao?idProposicao=363174. Acesso em: 14 dez. 2018.

\subsection{Legislação Citada}

BRASIL. Decreto-lei no 2.848, de 7 de dezembro de 1940 (Código Penal). Rio de Janeiro, 1940. Disponível em: www.planalto.gov.br/ccivil_03/decreto-lei/Del2848compilado.htm. Acesso em: 14 dez. 2018.

BRASIL. Lei no 6.001 de 19 de Dezembro de 1973 (Estatuto do Índio). Brasil, 1973. Disponível em: http://www. planalto.gov.br/ccivil_03/Leis/L6001.htm. Acesso em: 14 dez. 2018.

BRASIL. Constituição da República Federativa do Brasil de 5 de outubro de 1988. Disponível em: http://www. planalto.gov.br/ccivil_03/constituicao/constituicao.htm. Acesso em: 14 dez. 2018.

CÂMARA DOS DEPUTADOS. Regimento interno da Câmara dos Deputados: aprovado pela Resolução no 17, de 1989, e alterado até a Resolução no 20, de 2016. 18. ed. Brasília: Câmara dos Deputados; Edições Câmara, 2017. OIT. Organização Internacional do Trabalho. Convenção $n^{\circ} 169$ sobre povos indígenas e tribais e Resolução referente à ação da OIT / Organização Internacional do Trabalho. Brasília: OIT, 2011. $1 \mathrm{v}$.

SENADO FEDERAL. Resolução no 93 de 1970 (Regimento Interno do Senado Federal). Disponível em: https:// www25.senado.leg.br/documents/12427/45868/RISFCompilado.pdf/cd5769c8-46c5-4c8a-9af7-99be436b89c4. Acesso em: 14 dez. 2018.

\subsection{Referências}




\section{Democracia}

Humanos e

AZEVEDO, L. Comentários ao art. 50. In: CANOTILHO, J. J. Gomes; MENDES, G.; SARLET, I.; STRECK, L. (coord.). Comentários à Constituição do Brasil. São Paulo: Saraiva; Almedina, 2013. p. 2202-2207. [Edição digital].

BARDIN, L. Análise de conteúdo. São Paulo: Edições 70, 2011.

BARRETO, H. As disputas sobre direitos indígenas. Revista do Centro de Estudos Judiciários. Brasília, n. 22, p. 6369, jul./set. 2003.

BARRETO, H. Direitos indígenas: vetores constitucionais. Curitiba: Juruá, 2014.

BECKER, S.; SOUZA, O.; OLIVEIRA, J. A prevalência da lógica integracionista: negações à perícia antropológica em processos criminais do Tribunal de Justiça do Mato Grosso do Sul. Etnográfica, n. 171, p. 97-120, fev. 2013.

BIM, E. A participação dos povos indígenas e tribais: oitivas na Convenção 169 da OIT, Constituição Federal e Instrução Normativa n. 1 da Funai. Revista de Informação Legislativa, Brasília, n. 204, v. 51, p. 203-227, out. 2014.

DOUZINAS, C. O fim dos direitos humanos. Tradução Luzia Araújo. São Leopoldo: Unisinos, 2009.

DOUZINAS, C. The Paradoxes of Human Rights. Constellations, v. 20, n. 1, p. 51-67, mar. 2013.

FRANCO, F. Transformações na concepção universal e individual de Direitos Humanos por meio das perspectivas normativas dos povos indígenas e tribais. Direito e Desenvolvimento, v. 8, n. 1, p. 11-26, 26 set. 2017.

GREEN, L. Internal minorities and their rights. In: BAKER, J. (ed.). Group Rights. Toronto: University Of Toronto Press, 1994. p. 101-117.

GUTMANN, A. The challenge of multiculturalism in political ethics. Philosophy and Public Affairs. Princeton, NJ, v. 22, n. 3, July 1993, p. 171-206.

HEEMANN, T. Por uma releitura do direito dos povos indígenas: do integracionismo ao interculturalismo. Revista de Doutrina e Jurisprudência, Brasília, v. 1, n. 109, p.1-14, jul./dez. 2017.

HERRERA FLORES, J. Direitos humanos, interculturalidade e racionalidade de resistência. Seqüência: Estudos Jurídicos e Políticos, Florianópolis, p. 9-30, jan. 2002.

HERRERA FLORES, J. Colonialismo y violencia. Bases para una reflexión pos-colonial desde los derechos humanos. Revista Crítica de Ciências Sociais, n. 75, p. 21-40, out. 2006.

HERRERA FLORES, J. A (re)invenção dos direitos humanos. Florianópolis: Fundação Boiteux, 2009.

MENDES, G.; BRANCO, P. Curso de direito constitucional. 12. ed. São Paulo: Saraiva, 2017.

MOREIRA NETO, D. Direito da participação política: legislativa, administrativa, judicial: (fundamentos e técnicas constitucionais da legitimidade). Rio de Janeiro: Renovar, 1992.

MOYN, S. The Last Utopia: Human Rights in History. [S.I.]: The Belknap Press Of Harvard University Press, 2010. $337 \mathrm{p}$.

OLIVEIRA, A. Violência sexual, infância e povos indígenas: ressignificação intercultural das políticas de proteção no contexto das indígenas crianças. Revista Latinoamericana de Ciencias Sociales, Niñez y Juventud, Manizales, v. 14, n. 2, p. 1.177-1.190, 2016.

PAGE, S. "Narratives of blame" surrounding HIV and Aids eradication policies and sexual cultural practices in Malawi. In: LONGMAN, C.; BRADLEY, T. Interrogating Harmful Cultural Practices. Burlington: Ashgate, 2015. p. 67-80. PERUZZO, P. Direito à consulta prévia aos povos indígenas no Brasil. Revista Direito e Práxis, v. 8, n. 4, p. 2.7082.740, dez. 2017.

REBELO, R.; RAIO, R. Além da doutrina da proteção integral: rumo às perspectivas indígenas de infância. Revista de Sociologia, Antropologia e Cultura Jurídica, Brasília, v. 1, n. 3, p. 39-57, jan. 2017.

RODRIGUES, G. Direitos Humanos e multiculturalismo: o debate sobre o infanticídio indígena no Brasil. Revista Jurídica da Presidência, v. 15, n. 106, p.489-515, 27 set. 2013.

ROJAS GARZÓN, B.; YAMADA, É.; OLIVEIRA, R. Direito à consulta e consentimento de povos indígenas, quilombolas e comunidades tradicionais. São Paulo: Rede de Cooperação Amazônica - RCA; Washington, DC: Due Process of Law Foundation, 2016.

ROSA, M. Nós e os outros: concepções de pessoa no debate sobre infanticídio indígena no Congresso Nacional. Espaço Ameríndio, Porto Alegre, v. 8, n. 1, p. 163-193, jan./jun. 2014.

SANTOS, B. Por uma concepção multicultural dos direitos humanos. Revista Crítica de Ciências Sociais., n. 48, p. 11-32, jun. 1997.

SANTOS, B. Human Rights: A Fragile Hegemony. In: CRÉPEAU, F; SHEPPARD, C. (ed.). Human Rights and Diverse Societies: Challenges and Possibilities. Newcastle Upon Tyne: Cambridge Scholars Publishing, 2013. p. 17-26. 


\section{Humanos e \\ Democracia}

SANTOS-GRANERO, F. Hakani e a campanha contra o infanticídio indígena: percepções contrastantes de humanidade e pessoa na Amazônia brasileira. Mana, Rio de Janeiro, v. 17, n. 1, p. 131-159, abr. 2011.

SHACHAR, A. Multicultural Jurisdictions: Cultural differences and women's rights. Cambridge: Cambridge University Press, 2004.

SOUZA FILHO, C. O direito envergonhado. Revista lidh, v. 15, p.145-164, 1992.

SOUZA FILHO, C. Comentários aos arts. 231 e 232. In: CANOTILHO, J.; MENDES, G.; SARLET, I.; STRECK, L. (coord.). Comentários à Constituição do Brasil. São Paulo: Saraiva; Almedina, 2013. p. 4661-4679. [Edição digital].

THION, P. Questioning alternatives to legal regulation. In: WINTGENS, L. Legislation in context: essays in legisprudence. Ashgate Publishing Limited: Hampshire, 2007. p. 95-116.

TOSI, G.; SCORPION, W. As críticas de direita e esquerda aos Direitos Humanos. Problemata, v. 8, n. 1, p. 122-162, 11 abr. 2017.

WINTGENS, L. Legisprudence as a New Theory of Legislation. Ratio Juris, v. 19, n. 1, p. 1-25, mar. 2006.

WINTGENS, L. Legitimacy and legitimation from the Legisprudential perspective. In: WINTGENS, L. Legislation in context: essays in legisprudence. Ashgate Publishing Limited: Hampshire, 2007. p. 3-42. 